Vol. 2, No. 2, Juli - Desember 2018

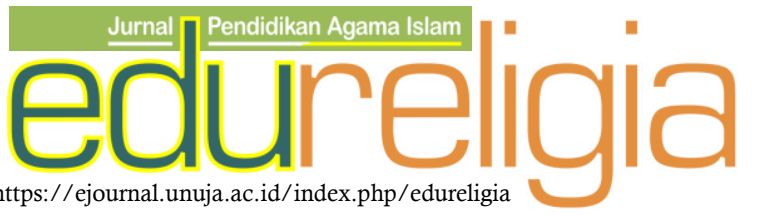

\title{
POLA INTEGRASI NILAI-NILAI KEPESANTRENAN DALAM MENGIMPLEMENTASIKAN BUDAYA RELIGI DI UNIVERSITAS NURUL JADID
}

\author{
Faizin $^{1}$; Farhah ${ }^{2}$ \\ Universitas Nurul Jadid, Paiton, Probolinggo
}

\section{Info Artikel \\ Sejarah Artikel: \\ Diterima; Juli 2018 \\ Disetujui; Agusuts 2018 \\ Dipublikasikan; \\ September 2018}

Keywords:

integrasi nilai

kepesantrenan; budaya

religi

\begin{abstract}
The uniqueness of universities in Islamic boarding schools Through the curriculum collaboration of Nurul Jadid University strives to produce excellent Islamic boarding school graduates not only in accordance with their respective potentials but also to have a religious understanding that influences such as the literary ability and furudhul's understanding ainiyah. The presence of Tri logi and the five awareness students were able to interpret the leaders, lecturers and students of the University of Nurul Jadid to bring about actual changes in civilization, therefore the researcher discussed the integration of Islamic values the nurul jadid university, to find out the understanding of the Tri logi objectives. and Panca awareness of students, both from leaders, lecturers and students who have never received an education in the Nurul Jadid boarding school. qualitative reception analysis method, with a descriptive-qualitative approach. The research subject was at Nurul Jadid Paiton Probolinggo
\end{abstract}

(C) 2018 Fakultas Agama Islam Universitas Nurul Jadid

Korespondensi:

ISSN 2549-4821

${ }^{1}$ Universitas Nurul Jadid, Paiton, Probolinggo E-ISSN 2579-5694 


\section{PENDAHULUAN}

Islamic boarding school "pesantren stems from "santri". The word pesantren refers to a place where the santri devotes most time to live and acquire knowledge". ${ }^{\mathrm{i}}$ Lembaga pendidikan Islam produk budaya Indonesia tertua adalah pesantren. Tentunya lembaga pondok pesantren diakui memiliki andil yang besar terhadap perjalanan sejarah bangsa. ${ }^{\text {ii }}$

Dalam perkembangannya, pondok pesantren semakin memperluas wilayah garapannya tidak hanya mengakselerasikan mobilitas vertikal (dengan penjejalan materi-materi keagamaan), tetapi juga mobilitas horisontal (kesadaran social). Pesantren tidak lagi berkutat pada kurikulum yang berbasis keagamaan (regional-based curriculum), The education "system" is a social system, ${ }^{\text {iii }}$ dan cenderung melangit, tetapi juga kurikulum yang menyentuh persoalan kekinian masyarakat (society-based curriculum. Dengan demikian, pesantren tidak bisa didakwa hanya sebagai lembaga keagamaan murni, akan tetap (seharusnya) menjadi lembaga sosial yang hidup yang terus merespon carut marut persoalan masyarakat di sekitarnya. ${ }^{\text {iv }}$ Bagi santri sangat dibutuhkan kemampuannya yang trampil dalam segala bidang untuk memberikan kontribusi mereka dimasa depan, atau pada saat bermasyarakat In the knowledge society, what are the skills and capabilities required of young peopleto make their contribution to the future? Multiple voices from a range of sources claimthat what is now paramount for young people is the need to become better learners and generators of knowledge. ${ }^{v}$ knowledge society learners will need todevelop an appreciation of the differences between information and knowledge $e^{v i}$ Yang kemudian mengharuskan santri pandai dalam mengatasai semua persoalan yang akan dihadapi.

Pesantren sebagai lembaga pendidikan Islam merupakan salah satu jawaban dari upaya menghadapi tantangan globalisasi, pengaruh lingkungan dan upaya dalam menyiapkan out put yang siap pakai. ${ }^{\text {vii }}$ Merujuk pada konsep pendidikan karakter dalam mewujudkan aspek kebiasaan santri maka diintegrasikan melalui program pesantren yang mencerminkan adanya misi karakter pesantren.Nilai-nilai fundamental agama perihal pendidikan karakter terpadu secara koheren. Internalisasi dapat diwujudkan melalui sarana kegiatan pesantren yang berkesinambungan dengan nilai-nilai trilogi santri dan panca kesadaran santri. ${ }^{\text {viii }}$
Hampir semua pesantren telah mendirikan Perguruan Tinggi dalam kompleks pesantren, begitu pula pondok pesantren Nurul Jadid.Universitas Nurul Jadid merupakan lembaga pendidikan formal tertinggi di pondok pesantren Nurul Jadid. Universitas Nurul Jadid terdiri dari empat Fakultas yaitu Fakultas Agama Islam, Fakultas Teknik, Fakultas Kesehatan dan Fakultas Humaniora.Sebagaimana Perguruan Tinggi baru pada umumnya, Universitas Nurul Jadid banyak mengalami perubahan mulai dari infrastruktur, akademik, keorganisasian dan lain-lain. Hal tersebut tentunya diimbangi dengan pemenuhan kebutuhan mulai dari pimpinan, dosen dan karyawan Universitas.

Kehadiran Perguruan Tinggi di pesantren diharap dapat meningkatkan mutu pendidikan pesantren yang sesuai dengan adat dan budaya pesantren tersebut, tanpa melepas nilai-nilai kepesantrenan yang telah ada dan menjadi ruh dalam setiap kegiatan di pesantren. Dengan demikian diharapkan nilai-nilai kepesantrenan di pondok pesantren Nurul Jadid (Trilogi Santri \& Panca Kesadaran Santri) melebur dalam semua kegiatan dan proses pembelajaran di Universitas Nurul Jadid. Agar perkembangan pesantren dengan adanya Perguruan Tinggi tidak menjadi batu sandungan bagi pesantren dan santri untuk tetap memegang teguh dan mempertahankan nilai-nilai kepesantrenan yang merupakan titah dari pendiri dan pengasuh pertama pondok pesantren Nurul Jadid KH. Zaini Mun'im.

\section{KAJIAN KONSEPTUAL}

\section{Integrasi Nilai-Nilai Kepesantrenan}

Integrasi berasal dari kata "integer" yang memiliki makna keseluruhan. ${ }^{\text {ix }}$ Menurut Sanusi, integrasi merupakan satu kesatuan yang utuh, tidak terpecah belah dan merupakan kebutuhan dan atau kelengkapan anggota-anggota yang membentuk suatu kesatuan dengan jalinan hubungan yang erat, harmonis dan mesra antara anggota kesatuan itu. ${ }^{\mathrm{x}} \mathrm{Hal}$ ini antara nilai-nilai kepesantrenan dan perguruan tinggi dapat bersinergi, dibawah naungan yayasan pondok pesantren Nurul Jadidid. Integrasi sistem pembelajaran yang ditetapkan oleh kurikulum perguruan tinggi dilakukan agar pesantren tidak kehilangan relevansi dan kebutuhan riil yang akan dihadapi komunitas pendidikan Islam. Djuwaeni Irsyad menyatakan bahwa integrasi sistem pembelajaran dilakukan dengan cara 
mengintegrasikan, menyatupadukan, menggabungkan dan mempersatukan dua hal atau lebih menjadi satu. ${ }^{\text {i }}$

Kata nilai didalam kamus besar Bahasa Indonesia berarti harga, Nilai memiliki makna berbeda jika berada pada konteks yang berbeda. Dalam konteks akademik nilai bisa berarti angka kepandaian, "rata - rata nilai mata pelajaran matematika". Dalam konteks yang lain nilai berarti kadar, "nilai gizi ."xii Sedangkan yang dimaksud nilai adalah standar tingkah laku, keindahan keadilan, kebenaran dan efisiensi yang mengikat manusia dan seharusnya dijalankan serta dipertahankan. ${ }^{\text {xii }}$ Sedangkan Menurut Onong Uchjana Effendi "Nilai merupakan pandangan, cita-cita, adat kebiasaan dan lain-lain dan dapat menimbulkan tanggapan emosional pada seseorang ataupun masyarakat tertentu." xiv

Teori internalisasi nilai dalam pembelajaran merupakan penyatuan dan penanaman nilainilai Islam agar menjadi sebuah watak dan tabiat yang dimiliki oleh peserta didik. nilainilai yang banyak disebuatkan secara eksplisit dalam al-Qur'an dan al-hadist yang kesemuanya terangkum dalam ajaran akhlak yang meliputi akhlak dalam hubungannya dengan Allah, dengan diri sendiri, dengan sesama manusia, dengan alam dan makhluk lainnya, sebagaimana termaktub didalam Trilogi santri (حسن الأدب مع الله ومع الخلق). Kedua, nilai-nilai uneversal yang diakui adanya dan dibutuhkan oleh seluruh umat manusia karena hakikatnya sesuai dengan fitroh manusia seperti, cinta damai, mengahargai hak asasi manusia, keadilan, demokrasi, kepedulian sosial dan kemanusiaan. ${ }^{\mathrm{xv}}$

Islam adalah agama yang nilai ajarannya tidak bertentangan dengan ideologi Pancasila, yang berimplikasi kepada kuatnya ketahanan ideologi santri terhadap Pancasila. $^{\text {xvi }}$ Nilai- nilai kepesantren ditanamkan mulai sejak pertama kali peserta didik atau santri masuk menjadi warga pesantren. Penanaman nilai-nilai kepesantrenan itu dilaksanakan baik melalui pembelajaran di lembaga formal dan melalui kehidupan sehari-hari di pesantren ${ }^{\text {xii }}$ Nilainilai yang diharapkan muncul dalam karakter seorang individu lulusan perguruan tinggi di Pondok Pesantren Nurul Jadid harus dilatih dan dididik, supaya menjadi kebiasaan (habit). ${ }^{\text {xviii }}$

Pesantren berasal dari pe-santri- an yang berarti tempat tinggal santri yang dikenal sebagai murid ${ }^{\text {xix }}$ Secara etimologi menurut
Wahjoetomo kata pondok berasal dari bahasa Arab yang artinya hotel, ${ }^{\mathrm{xx}}$ funduk. ${ }^{\mathrm{xx}}$ Pesantren sebagai lembaga pendidikan agama Islam yang tumbuh dan diakui oleh masyarakat sekitar dalam lingkup pendidikan formal dikenal dan disebut sebagai boarding school. ${ }^{x i i}$ pesantren sebagai kelas literacy (melek huruf), yaitu orang yang berusaha mendalami kitab klasik yang

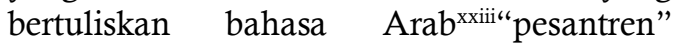
sendiri berasal dari kata Ba- hasa Sansekerta atau Pali, "shastri", adalah istilah untuk menyebut sarjana yang mampunyai keahlian dalam kitab-kitab suci dan kitab Klasik. ${ }^{\text {xiv }}$ Istilah pondok pesantren dimaksudkan adalah bentuk pendidikan ke-Islaman yang melembaga di Indonesia. Kata pondok (kamar, gubuk, rumah kecil) dalam bahasa Indonesia dengan menekankan kesederhanaan bangunan. ${ }^{x x}$ Pondok pesantren adalah lembaga pendidikan Islam untuk memahami dan mengamalkan ajaran Islam dengan menekankan pentingnya moral agama. $^{\text {xxvi }}$

Pesantren sebagai lembaga pendidikan yang mentransfer nilai dan pengetahuan (transfer of values and knowledge), memiliki fungsi sosial. ${ }^{x x v i i}$ Pesantren adalah "Bapak" pendidikan islam di Indonesia, berdiri karena adanya tuntutan dan kebutuhan zaman. ${ }^{\text {xxvii }}$ pesantren, telah memiliki fungsi ganda, sebagai transformasi nilai dengan pendekatan amar ma'ruf nahi mungkar (fungsi klasik) dan fugsi pengembangan masyarakat, sebagai sarana peningkatan dan kesejahteraan masyarkat (fungsi pengembangan). ${ }^{x i x}$ Abdurrahman Wahid mendefinisikan pesantren sebagai tempat santri hidup..$^{\mathrm{xx}}$ lembaga pendidikan Islam yang unik di Indonesia. ${ }^{\text {xxi }}$

Zamakhsyari Dofier mengungkapkan bahwa kyai sebagai arsitek kemasyarakatan (social engineer) harus memperthatikan selera masyarkat. ${ }^{\text {xxxii }}$

Universitas Nurul Jadid merupakan Perguruan tinggi pusat ilmu pengetahuan (centre of knowledge), pusat pengembangan dan sumber daya manusia (human recources). ${ }^{\text {xxiii }}$ pembelajaran dengan mengintegrasikan, menyatu padukan, menggabungkan dan mempersatukan (dua hal atau lebih menjadi satu. ${ }^{\text {xxiv }}$ pesantren sebagai model institusi pendidikan yang memiliki keunggulan, baik dari sisi transmisi dan internalisasi moralitas umat Islam.

\section{Budaya Religi}

Budaya dalam kamus Besar Bahasa Indonesia (KBBI), berarti adat istiadat. 
menurut Kotter dan Heskett, dapat diartikan sebagai totalitas pola perilaku, kesenian, kepercayaan, kelembagaan, dan semua produk lain dari karya dan pemikiran manusia yang mencirikan kondisi suatu masyarakat atau penduduk yang ditransmisikan bersama. $^{\text {xxxv }}$ Jadi definisi kebudayaan, yaitu kaidah universal tentang sesuatu yang ada, kehidupan, dan manusia, yang berwujud keyakinan, seni, pemikiran, aturan, dan kepribadian, sehingga menjadi sebuah konstruksi yang dibentuk oleh agama, filsafat. ${ }^{\text {xxvi }}$

Sedangkan Religi adalah suatu kesatuan unsur yang komprehensif, yang menjadikan seseorang disebut sebagai orang yang beragama (being religious). ${ }^{x x v i i}$ Tujuannya untuk mengenalkan kepada mahasiswa tentang pengertian agama dan tata cara pelaksanaan agama tersebut dalam kehidupan sehari-hari, karenaperguruan tinggi di Pesantren tetap memiliki fungsi sebagai transformasi ilmu-ilmu agama (tafaqquh fiddin) dan penanaman (internalisasi) nilai-nilai Islam (Islamic values), dan juga kontral sosial ${ }^{\mathrm{xxxviii}}$

\section{METODE PENELITIAN}

Penelitian ini bertujuan untuk mengetahui bagaimana pola integrasi nilai-nilai kepesantrenan di Universitas Nurul Jadid Adapun Penelitian ini menggunakan pendekatan deskriptif-kualitatif. Subjek penelitian Universitas Nurul Jadid Paiton Probolinggo informan dalam penelitian ini Civitas Akademika Universitas Nurul Jadid dengan pelaporan informan secara terperinci dan disusun dalam sebuah latar ilmiah. ${ }^{\text {xxix }}$ peranan yang sangat penting dari apa yang harus diteliti yaitu persoalan tentang manusia yang diteliti. ${ }^{\mathrm{xl}}$

Objek penelitian Integrasi nilai-nilai kepesantrenan yang dalam hal ini Trilogi dan Panca Kesadaran Santri pondok pesantren Nurul Jadid Paiton Probolinggo. pengumpulan data yang diupayakan dalam penelitian ini adalah interview merupakan teknik pengumpulan data untuk mendapatkan informasi secara langsung. ${ }^{\text {xli }}$

\section{PEMBAHASAN}

Perguruan tinggi yang ada dibawah naungan pondok pesantren kebijakan dan kepusannya sentral kepada pemimpin tertinggi dalam pesantren atau yang disebut dengan istilah pengasuh yang tentunya sang kyailah yang menjadi pimpinannya pesantren. ${ }^{\text {xli }}$ Eksistensi kyai merupakan figur utama ${ }^{x l i i i}$ sebagai perintis dan penerus pesantren dan sebagai pemegang kebijakan.
Pesantren di bawah pimpinan kyai atau ulama dibantu oleh para ustadz yang hidup bersama di tengah-tengah para santri serta masjid atau surau sebagai pusat kegiatan peribadatan keagamaan ${ }^{\text {xliv }}$ dan pembelajaran secara umum.

Pembinaan yang dilakukan internalisasi di Universitas Nurul jadid adalah pembinaan yang mendalam dan menghayati nilai-nilai agama yang dipadukan dengan nilai-nilai pendidikan secara utuh yang sasarannya menyatu dengan kepribadian peserta didik, sehingga akan menjadi karakter perilaku peserta didik. Internalisasi adalah sebagai penghayatan, pendalaman, penguasaan secara mendalam melalui binaan, bimbingan, ${ }^{\text {xlv }}$ Dengan demikian internalisasi merupakan suatu proses penanaman pola pikir, sikap dan perilaku ke dalam diri pribadi seseorang melalui pembinaan, bimbingan dan sebagainya agar menguasai secara mendalam suatu nilai sesuai dengan standar yang diharapkan dalam hal ini Pondok pesantren Nurul Jadid. $^{\text {xlvi }}$

Pesantren terus berkembang seiring perkembangan jaman dan terus berusaha agar sesuai dengan fungsi utama pondok pesantren; Pertama, sebagai media pengkaderan bagi pemikir-pemikir agama (centre of excellent). Kedua, sebagai lembaga yang mencetak sumber daya manusia (SDM). Dan ketiga, sebagai lembaga yang memberdayakan masyarakat, oleh sebab itu, pondok pesantren Nurul Jadid tetap menjaga tali silaturahim antar alumni yang telah pulang ke tengah-tengah masyarakat dan pengasuh dan dibentuk organisai yang mengarah kepada pemberdayaan alumni meliputi pemberdayaan yang berdampak pada pesantren, diri alumni, dan masyarakat. ${ }^{\text {xlvii }}$ Selain itu, pesantren juga dipahami sebagai bagian yang terlibat aktif dalam proses perubahan social ditengah perubahan yang terjadi di Indonesia. ${ }^{\text {xliii }}$ Dalam mengimplementasikan tiga fungsi tersebut pondok pesantren Nurul Jadid menitikberatkan pada adanya Trilogi Santri dan Panca Kesadaran Santri (al-wa'iyyat alkhamsah), yang meliputi : Trilogi Santri

a) الاهتمام بالفروض العينية

(Memperhatikan kewajiban-kewajiban fardlu 'ain)

b) الاهتمام بترك الكبائر

(Mawas diri dengan meninggalkan dosadosa besar) 
حسن الادب مع الله ومع الخلق حمالق

(Berakhlak baik pada Allah dan
makhlukNya)

Point-point ini adalah hal-hal yang harus diperhatikan oleh setiap umat islam, dari tiga point inilah yang menjadi landasan adanya lima kesadaran yang sering dikenal dengan Panca Panca Kesadaran Santri:

a) الو عي الديني (kesadaran beragama),

b) الوعي العلمي (kesadaran berilmu),

c) الوعي الاجتماعي (kesadaran bermasyarakat),

d) الوعي الحكومي والثعبي الآناعي (kesadaran berbangsa \& bernegara),

e) الوعي النظا مي (kesadaran berorganisasi).

Panca Kesadaran Santri inilah yang menjadi titik tolak dan citra bagi diri semua kultur masyarakat pesantren di pondok pesantren Nurul Jadid, baik dalam proses pembentukan jati diri ketika masih nyantri, hingga berperan aktif dalam membantu pengembangan pesantren dan membangun masyarakat. Universitas yang ada dilingkungan pondok pesantren juga sangat di penagrruhi oleh beberapa pihak, atau masyarakat pesantren yang nantinya dikembalikan lagi kepada the stake holder, ${ }^{\text {xlix }}$ yaitu masyarakat di lingkungan pesantren dan sekitarnya. Sesuai dengan tujuan pendidikan yang pendiri tanamkan yaitu "ingin mendidik manusia yang muslim, berakhlak karimah, bertaqwa kepada Allah, berilmu dan berketerampilan yang cukup, ${ }^{1}$ dan disesuaikan dengan perkembangan dan kecendrungan masyarakat. Hal itu sudah tercakup dalam Tri logi dan Panca kesadaran santri. Dan utuk pemahaman agama sangat perlu dipahami bagaimana kondisi sosial masyarakat pada suatu tempat yang antara satu tempat dengan tempat lainnya. ${ }^{\text {li }}$

Pondok pesantren Nurul Jadid Paiton Probolinggo merupakan lembaga pendidikan islam yang memegang teguh nilai Trilogi Santri dan Panca Kesadaran Santri. Trilogi Santri dan Panca Kesadaran Santri adalah nilai dasar yang merupakan buah pikir dari pendiri sekaligus pengasuh pertama pondok pesantren Nurul Jadid KH. Zaini Mun'im, nilai inilah yang kemudian menjadi ruh dalam semua aspek kegiatan baik pesantren ataupun lembaga dibawah pesantren. Dimana nilai Trilogi Santri dan Panca Kesadaran Santri harus dijadikan landasan utama perencanaan dan pembentukan program-program di lembaga dibawahnya termasuk juga Universitas Nurul Jadid.

Sebagai lembaga tinggi yang ada dibawah naungan pondok pesantren Nurul Jadid, Universitas Nurul Jadid harus menyesuaikan semua program yang direncanakan dengan nilai Trilogi Santri dan Panca Kesadaran Santri termasuk visi misi Universitas Nurul Jadid sebagaimana yang disampaikan oleh Rektor Universitas Nurul Jadid bapak KH. Abdul Hamid Wahid, M.Ag sebagai berikut:

"Trilogi Santri dan Panca Kesadaran Santri itu nilai dasar yang harus dimiliki oleh santri Nurul Jadid secara keseluruhan dan diusahakan untuk dikembangkan dalam bentuk kegiatan-kegiatan baik di pesantren maupun lembaga termasuk Universitas Nurul Jadid. Universitas Nurul Jadid itu lembaga pendidikan tinggi yang ada di lingkungan pondok pesantren, jadi dengan sendirinya visi misi Universitas Nurul Jadid harus sesuai dengan visi misi pesantren walaupun tugas yang diemban perguruan tinggi sebagai lembaga pengembangan ilmu tentu mengemban tugas khusus."

Dari keterangan yang disampaikan oleh Rektor Universitas Nurul Jadid bahwa nilai Trilogi Santri dan Panca Kesadaran Santri merupakan nilai utama yang dihidupkan dan dijunjung tinggi di pondok pesantren Nurul Jadid, yang kemudian akan menjadi ruh dalam dalam semua aktivitas santri dan kegiatan-kegiatan kelembagaan termasuk di Universitas Nurul Jadid. Universitas Nurul Jadid merupakan lembaga pendidikan tinggi yang pada hakikatnya memiliki tugas khusus yang harus diemban, akan tetapi Universitas Nurul Jadid sebagai lembaga pendidikan tinggi di bawah naungan pondok pesantren dituntut untuk melaksakan tugas khusus sebagai lembaga pendidikan tinggi sekaligus menerapkan nilai-nilai kepesantrenan didalamnya mulai dari visi misi dan program-program kelembagaan.

Sebagai nilai dasar tentunya implementasi nilai Trilogi Santri dan Panca Kesadaran Santri tidak serta merta dipahami secara tekstual akan tetapi harus dikembangkan dengan berbagai jalur dan berbagai cara agar tujuan dari nila-nilai tersebut dapat terwujud dan dapat dilaksanakan dengan mudah, hal ini juga disampaikan oleh Rektor Universitas Nurul Jadid sebagai berikut:

"Trilogi Santri dan Panca Kesadaran Santri itu nilai-nilai yang perlu dikembangkan, jadi semua itu dilaksanakan dalam berbagai jalur dan berbagai cara. Seperti kalau di 
Universitas Nurul Jadid ini salah satunya dalam kurikulum, ekstrakurikuler dan kokurikuler semua itu dilaksanakan dalam rangka mewujudkan Trilogi dan Panca Kesadaran Santri.”

Sebagaimana keterangan yang disampaikan oleh Rektor Universitas Nurul Jadid sebelumnya bahwa Universitas Nurul Jadid adalah lembaga pendidikan tinggi yang mengemban tugas khusus dan ada dibawah naungan pondok pesantren. Dalam keterangan selanjutnya, Rektor Universitas Nurul Jadid sekaligus Kepala Pesantren pondok pesantren Nurul Jadid mengutarakan bahwa dalam mengimplementasikan nilai Trilogi Santri dan Panca Kesadaran Santri sebagai bentuk integrasi nilai, Universitas Nurul Jadid menyampaikannya melalui beberapa cara karena Trilogi Santri dan Panca Kesadaran Santri merupakan nilai yang harus dikembangkan, di Universitas Nurul Jadid salah satunya melalui perencanaan dan pelaksanaan kurikulum, ekstrakurikuler dalam bentuk kegiatan kemahasiswaan dan kokurikuler.

Dalam kurikulum bentuk integrasi penanaman nilai Trilogi Santri dan Panca Kesadaran Santri di Universitas Nurul Jadid dilakukan dengan berbagai cara, karena sebagai lembaga pendidikan tinggi Universitas Nurul Jadid juga memiliki standar khusus dalam menyusun kurikulum yang berasal dari Kementrian Riset Teknologi dan Perguruan Tinggi juga dari Direktorat Jendral Pendidikan Islam, seperti yang disampaikan oleh Wakil Rektor II Bapak Drs. H. Hambali, M.Pd, sebagai berikut:

"Kurikulum di perguruan tinggi itu ada ketentuan baku yaitu kurikulum wajib yang berasal dari Kemenristekdikti, juga kurikulum berdasarkan Dirjen Pendidikan Islam, dan ada kurikulum muatan lokal, dimuatan lokal inilah kemudian kita sesuaikan dengan nilai dan norma kurikulum yang ada dipesantren. Untuk mengimplementasikan salah satu upayanya adalah menyesuaikankan kurikulum universitas dengan kurikulum pesantren dan kemudian ada kurikulum yang wajib diikuti oleh mahasiswa baru semester satu dan dua tentang furudhul 'ainiyah yang pelaksanaannya diserahkan kepada Lembaga Integrasi Kokurikuler pada Lembaga Kendali Mutu Keagamaan. Hal tersebut sebagai upaya yang dilakukan Universitas, masak baca Al-fatihah saja tidak lancar, menulis Al-quran tidak bisa, pengetahuan tentang furudhul 'ainiyahnya juga tidak bisa, maka ini salah satu bentuk untuk menepis dan menyadarkan lulusan dan mahasiswa pesantren minimal furudhul 'ainiyahnya seselai."

Dari keterangan diatas dapat diketahui bahwa dalam menanamkan nilai-nilai kepesantrenan atau nilai-nilai keagamaan. Karena Indonesia adalah negara Islam terbesar di dunia, pertanyaan yang sedang berlangsung untuk komunitas Islam adalah bagaimana menciptakan pemuda muslim yang kuat, saleh, danmasyarakat Islam yang setia dalam konteks negara modern, globalisasi, dan sekuler. Demikian,mengembangkan sistem pendidikan hibrida di sekolah Islam secara lahiriah mendukung nasional kebijakan pembangunan sambil berusaha keras untuk menetapkan nilai-nilai Islam sebagai dasar untuk kehidupan publik di Indonesia, Since Indonesia is the world's largest Islamic country, the ongoing question for the Islamic community has been how to create a strong, pious, and faithful Islamic society in the context of a modernizing, globalizing, and secular state. Thus, developing a hybrid educational system in Islamic school has outwardly supported the national development policies while striving to firmly establish Islamic values as the foundation for public life in Indonesia ${ }^{\text {lii }}$

Universitas Nurul Jadid tidak hanya memperhatikan kurikulum-kurikulum yang diatur oleh Kementrian Riset Teknologi dan Perguruan Tinggi dan juga kurikulum dari Direktorat Jendral Pendidikan Islam saja. Akan tetapi Universitas Nurul Jadid tetap mengedepankan kurikulum pesantren, dengan cara dimasukkan kedalam kurikulum muatan lokal, dan memberikan mata kuliah wajib seperti mata kuliah kepesantrenan, aswaja/ke NU-an, baca tulis Al-quran dan furudhul 'ainiyah untuk mahasiswa semester satu dan dua secara keseluruhan sebagai bentuk penanaman awal nilai-nilai kepesantrenan dan nilai-nilai keagamaan.

Mahasiswa sebagai komponen utama dari kehidupan kampus, merupakan aset yang berharga demi kelangsungan nilai dan sistem dalam pendidikan kampus di masa depan. Selain itu, mahasiswa adalah pilar penyanggah perjuangan generasi ke generasi di mana peran sosialnya didalam sejarah selalu dituntut untuk ditempatkan diposisi terhormat dan berwibawa dari aspek spiritual, intelektual, dan emosional. liii

Melalui kolaborasi kurikulum Universitas Nurul Jadid berusaha menghasilkan lulusan- 
lulusan pesantren yang unggul bukan hanya dalam akademik sesuai potensi masingmasing akan tetapi memiliki pemahaman keagamaan yang mumpuni seperti kemampuan baca tulis Al-qur'an dan pemahaman furudhul 'ainiyah. Hal tersebut sebagai upaya Universitas Nurul Jadid mendorong dan meningkatkan kemampuan pemahaman keagamaan, yang kemudian pelaksanaannya ditangani oleh lembaga dibawahnya yaitu Lembaga Integrasi Kokurikuler. Lembaga yang menangani kegiatan kemahasiswaan khusus yang berkaitan dengan pesantren. Sebagaiamana keterangan yang disampaikan oleh Rektor Universitas Nurul Jadid, sebagai berikut:

"LIK ini bertugas untuk mengelola kelebihan bersama yakni kampus UNUJA yang ada dibawah pesantren ini didalam sebuah system, dan disitu LIK menangani Pomas Pomasi, LKMK dan Lembaga Bahasa."

Lembaga Integrasi Kokurikuler merupakan salah satu Lembaga yang sengaja dibentuk oleh Universitas Nurul Jadid sebagai wadah untuk mengelola pelaksanaan kegiatan kemahasiswaan yang berhubungan dengan pondok pesantren seperti pondok mahasiswa, LKMK (Lembaga Kendali Mutu Keagamaan) yang menangani pembinaan mahasiswa sesuai kurikulum pesantren yang telah dijelaskan sebelumnya dan lembaga bahasa. Jadi semua kegiatan kemahasiswaan yang berbasis kepesantrenan dibawah tanggung jawab Lembaga Integrasi Kokurikuler.

Sebagai lembaga dibawah naungan pondok pesantren bentuk integrasi yang dilakukan oleh Universitas Nurul Jadid sebagai bentuk penanaman nilai kepesantrenan selain dalam hal akademik, juga dalam perencanaa dan pelaksanaan peraturan kode etik yang ada di Universitas, sebagaimana yang disampaikan oleh Wakil Rektor III Bapak M. Noer Fadli Hidayat, M.Kom, sebagai berikut:

"Dasar hukum pembentukan kode etik di Universitas Nurul Jadid merupakan gabungan dari kode etik Undang-Undang Pendidikan Tinggi, Menristekdikti berkaitan dengan Standar Nasional Perguruan Tinggi, Statuta dan peraturan yang ada di pondok pesantren Nurul Jadid. Salah satunya cara berpakaian dan cara berhubungan harus sesuai dengan standar pesantren bahkan sanksinyapun juga harus sesuai dengan sanksi yang ada dipesantren. Andaikan terjadi pelanggaran yang melibatkan mahasiswa maka akan dikenakan sanksi sesuai sanksi dari pesantren tidak hanya mahasiswa yang ada didalam termasuk juga mahasiswa yang ada di luar pesantren. Karena sekarang di UNUJA itu yang menentukan dia akan disanksi apa itu Mahkamah Pesantren."

Dari keterangan yang disampaikan oleh wakil rektor tiga ini setidaknya dapat ditarik kesimpulan bahwa pola integrasi yang di bangun oleh Universitas Nurul Jadid bukan hanya dari sisi akademik dan kegiatan kemahasiswaan saja, akan tetapi juga pada titik yang paling penting yakni peraturan kode etik. Selain mematuhi peraturan kode etik sesuai Undang-Undang Pendidikan Tinggi, Menristekdikti dan Statusnya sebagaimana perguruan tinggi pada umumnya, Universitas Nurul Jadid juga memasukkan peraturan pesantren Nurul Jadid didalamnya seperti tatacara berbusana yang baik dan sesuai dengan nilai pesantren, tata cara bersosial atau bergaul, dan semua hal yang berkaitan dengan peraturan pondok pesantren, ini sebagai bentuk integrasi nilai yang dilaksanakan. Jadi tidak ada tali pemutus baik dalam hal penetapan peraturan dan pengambilan keputusan sanksi, semua pelanggaran peraturan yang sifatnya melanggar peraturan pesantren meskipun tidak tercantum dalam Undang-Undang Pendidikan Tinggi, Menristekdikti dan Statuta akan tetap diproses sebagaimana mestinya di Mahkamah Pesantren. Dan Universitas Nurul Jadid mentaati dan menjalankan segala bentuk sanksi yang dikeluarkan oleh Mahkamah Pesantren.

Bukan hanya kepada mahasiswa pola integrasi nilai kepesantrenan yang terjadi di Universitas Nurul Jadid juga berlaku dikalangan dosen dan karyawan, namun proses pengenalan nilainya masih bersifat alami. Seperti yang disampaikan oleh Rektor Universitas Nurul Jadid sebagai berikut:

"Pengenalan nilai Trilogi dan Panca Kesadaran Santri secara khusus belum tapi pengenalan itu bisa melalui proses pergaulan dikampus dan dikantor, tentunya disana ada proses yang berjalan, dari situ secara tidak langsung juga terjadi sosialisasi dan kemudian penerapan aturan-aturan yang sesuai dengan karakter pesantren itu juga masuk didalamnya Trilogi dan Panca Kesadaran Santri, dengan demikian secara tidak langsung mereka bersosialisasi, berproses dalam pergaulan sekaligus mengamalkan Trilogi dan Panca Kesadarn Santri." 
Dari keterangan yang disampaikan oleh Rektor Universitas Nuru Jadid bahwa pengenalan nilai kepesantrenan berjalan dengan alami dikalangan dosen dan karyawan. Mereka mengenal dan menerapkan nilai-nilai tersebut melalui proses pergaulan sehari-hari, dimana dosen dan karyawan yang berasal dari luar dapat menyesuaikan diri melalui proses yang berjalan. Jadi nilai Trilogi Santri dan Panca Kesadaran Santri dapat mereka kenal melalui para alumni yang juga menjadi dosen atau karyawan di Universitas Nurul Jadid.

Dengan demikian dapat diketahui bahwa pola integrasi nilai kepesantrenan yang dibangun oleh Universitas Nurul Jadid diwujudkan dengan berbagai cara mulai dari kurikulum, kegiatan lembaga kendali mutu keagamaan dalam LIK (Lembaga Integrasi Kokurikuler) dan penerapan peraturan. Semuanya di susun khusus sebagai bentuk untuk mewujudkan nilai-nilai kepesantrenan pondok pesantren Nurul Jadid. Adapun Teknik pembinaan yang dilakukan melalui internalisasi di Universitas Nurul jadid adalah pembinaan yang mendalam dan menghayati nilai-nilai agama yang dipadukan dengan nilai-nilai pendidikan secara utuh yang sasarannya menyatu dengan kepribadian peserta didik, sehingga akan menjadi karakter perilaku peserta didik. Dengan demikian internalisasi merupakan suatu proses penanaman pola pikir, sikap dan perilaku ke dalam diri pribadi seseorang melalui pembinaan, bimbingan dan sebagainya agar menguasai secara mendalam suatu nilai sesuai dengan standaryang diharapkan dalam oleh Pondok pesantren Nurul Jadid. ${ }^{\text {liv }}$ Nilai-nilai tersebut bisa jadi dari berbagai aspek baik dari agama, budaya, sosial dan lain-lain. ${ }^{\text {lv }}$

Sistem asrama pada kehidupan pondok pesantren dan karakteristik kehidupan di dalamnya mendorong peserta didik agar mampu memenuhi dan menjalani tugas kehidupan sehari-hari dengan mandirilvi Pembelajaran kedisiplinan kepada mahasiswa dan santri menjadi program yang "wajib" untuk ditaati. ${ }^{\text {vii }}$ Kebiasaan untuk taat aturan merupakan konsekuensi yang harus ditaati oleh para santri di pesantren. .viii

Pondok mahasiswa agaknya menjadi sebuah fenomena baru era 90-an. Kehadirannya sebenarnya merupakan jawaban atas kegelisahan masyarakat terhadap komunitas mahasiswa yang cenderung menjaga jarak dengan kehidupan beragaman. ${ }^{\text {lix }}$
Integrasi memerlukan Interkoneksi antara satu disiplin ilmu dengan disiplin lainnya, bukan hanya sekedar kehadiran lembaga itu dalam satu naungan lembaga yang besar melainkan landasan antara kurikulum dalam satu lembaga memiliki keterkaitan atau memiliki landasan filosofis yang terintegrasi. ${ }^{1 \mathrm{x}}$

\section{KESIMPULAN}

Pada dasarnya pimpinan, dosen dan karyawan menerima dengan adanya integrasi nilai Trilogi dan Panca Kesadaran Santri ke dalam Universitas Nurul Jadid. Nilai ini dianggap perlu untuk diintegrasikan mengingat posisi Universitas Nurul Jadid yang ada dibawah naungan yayasa pondok pesantren Nurul Jadid. Akan tetapi dosen dan karyawan yang berasal dari luar atau bukan alumni pesantren cenderung asing dengan nilai Trilogi Santri dan Panca Kesadaran Santri, karena di Universitas Nurul Jadid tidak pernah diadakan pengenalan khusus mengenai nilai Trilogi Santri dan Panca Kesadaran Santri.

Pola integrasi nilai kepesantrenan di Universitas Nurul Jadid sudah terbentuk dan telah berjalan dengan baik dikalangan mahasiswa, Bagi dosen dan karyawan hanya bersifat integratif adaptif, maksudnya pola integrasi yang hanya berdasarkan penyesuaian diri, tidak ada pola khusus yang mengatur penanaman nilai Jadi pengenalan, penanaman dan penerapannya di kalangan dosen dan karyawan dilakukan dengan beradaptasi mengenali nilai kepesantrenan dari lingkungan mulai dari proses bergaul baik di kampus dan sekitarnya.

\section{DAFTAR PUSTAKA}

Syamsul Ma, 'POLA HUBUNGAN PATRON-CLIENT KIAI DAN SANTRI DI PESANTREN', TA'DIB, 2 (2010), 278.

ii H.Amin Haedar, Transformasi Pesantren, (Jakarta: Media Nusantara, 2007).3

iii sonja varbelow, 'INSTRUCTION, CURRICULUM AND SOCIETY: ITERATIONS BASED ON THE IDEAS OF WILLIAM DOLL', International Journal of Instruction, 5.1 (2012), 88-98.

iv Ahmadi, Ideologi Pendidikan Islam; Paradigma Humanisme Teosentris (Yokyakarta: Pustaka Pelajar, 2005).1

$\checkmark$ Anne Looney and Val Klenowski, 'Curriculum and Assessment for the 
Knowledge Society: Interrogating Experiences in the Republic of Ireland and Queensland , Australia', 19.3 (2008), 177-92 <https://doi.org/10.1080/095851708 02357496>

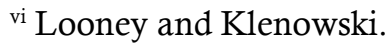

vii Akmal Mundiri and Irma Zahra, 'CORAK REPRESENTASI IDENTITAS USTADZ DALAM PROSES TRANSMISI PENDIDIKAN KARAKTER DI PESANTREN', JPII, 1 (2017), 21-35.

vii Akmal Mundiri and Afidatul Bariroh, 'TRANS INTERNALISASI PEMBENTUKAN KARAKTER MELALUI TRILOGI DAN PANCA KESADARAN SANTRI', IQRA' (Jurnal Kajian Ilmu Pendidikan), 1 (2018), 24-55.

ix S. Nasution, Asas- Asas Kurikulum (Jakarta: Bumi Aksara, 2006).162.

x S Sanusi, Integrasi Umat Islam (Bandung: Iqomatuddin, 1987).

xi Didin Saepudin2 Udi Fakhruddin1*, 'INTEGRASI DALAM SISTEM PEMBELAJARAN DI PESANTREN', Jurnal Pendidikan Islam' Ta'dibuna', 7.1 (2018), 94-113.

xii Ali Imran*** M.Nurhadi Amri*, Al Rasyidin** and *, 'INTEGRASI NILAI-NILAI KEISLAMAN DALAM PEMBELAJARAN BIOLOGI DI SMA ISLAM AL ULUM TERPADU MEDAN', Edu Riligia, 1 (2017), 487-501.

xiii Mukhibat, 'DERADIKALISASI DAN INTEGRASI NILAI- NILAI PLURALITAS DALAM KURIKULUM PESANTREN SALAFI HARAKI DI INDONESIA', Al-Tahrir, 14 (2014), 181-204.

xiv Onong Uchjana Effendi, Ilmu, Teori Dan FilsafatKomunikasi (Bandung: Citra Aditya Bakti, 2003).376.

xv Ahmadi, Ideologi Pendidikan Islam; Paradigma Humanisme Teosentris, (Yokyakarta: Pustaka Pelajar, 2005). 122

xvi Fatiyah, 'PEMAHAMAN SANTRI MAHASISWA TERHADAP NILAI-
NILAI PANCASILA', Jurnal Adabiyah, 17 (2017), 44-53.

xvii A.Muchaddam Fahham, 'PENDIDIKAN KARAKTER DI PESANTREN', Aspirasi, 4.3 (2013), 29-45.

xvii Risa Nopianti, 'PENDIDIKAN AKHLAK SEBAGAI DASAR PEMBENTUKAN KARAKTER DI PONDOK PESANTREN SUKAMANAH TASIKMALAYA', Patanjala, 10 (2018), 251-66.

xix Mansur Hidayat, 'MODEL KOMUNIKASI KYAI DENGAN SANTRI DI', Jurnal Komunikasi ASPIKOM, 2 (2016), 385-95.

${ }^{x x}$ Dhevin M Q Agus P W, 'MANAJEMEN PONDOK PESANTREN DALAM MENGINTE- GRASIKAN KURIKULUM PESANTREN DENGAN PENDIDI- KAN FORMAL', 5 (2013), 200.

xxi Muhamad Priyatna, 'MANAJEMEN PEMBELAJARAN PROGRAM KULLIYATUL MU'ALLIMIN ALISLAMIYAH (KMI) DI PONDOK PESANTREN MODERN ALIHSAN BALEENDAH BANDUNG', Jurnal Edukasi Islami Jurnal Pendidikan Islam, 6 (2017), 20.,

xxii Joko Paminto, Tina Rosiana, and Heri Triluqman Budisantoso, 'Implementasi Kurikulum 2013 Di Sekolah Pesantren Dengan Sistem Boarding School', Indonesian Journal of Curriculum and Educational Technology Studies, 6.1 (2018), 41-52.

xxiii Fitroh Hayati, 'Pesantren Sebagai Alternatif Model Lembaga Pendidikan Kader Bangsa', MIMBAR, XXVII (2011), 157-63 $<$ https://doi.org/10.29313/mimbar.v 27i2.324>.

xxiv Mukhibat, 'Meneguhkan Kembali Budaya Pesantren Dalam Merajut Lokalitas, Nasionalitas, Dan Globalitas', KARSA: Jurnal Sosial Dan Budaya Keislaman, 23.156 (2015), 17792

<https://doi.org/10.19105/karsa.v23 12.717>.

xxv ZULQARNAIN, 'Penanaman Nilai-Nilai Pendidikan Multikultural Di Pondok Pesantren D DI-AD Mangkoso Barru 
Sulawesi Selatan', Jurnal Al-Thariqah, 1.2 (2016), 193-205.

Sutrisno,

'IMPLEMENTASI PENDIDIKAN KARAKTER DI PONDOK PESANTREN MODERN MUHAMMADIYAH BOARDING SCHOOL ( MBS ) YOGYAKARTA IMPLEMENTATION OF CHARACTER EDUCATION IN PONDOK PESANTREN MODERN', Jurnal Pendidikan Luar Sekola, VI (2017), 509-25.

xxvii 'EKSISTENSI PESANTREN DAN DERADIKALISASI PENDIDIKAN ISLAM DI INDONESIA ( Menyemai Spirit Toleransi Dan Pendidikan Islam Multikultural ) Mualimul Huda Institut Agama Islam Negeri Kudus Abstrak P3M Sekolah Tinggi Agama Islam Negeri ( STAIN ) Curup - Bengkulu', Fokus: Jurnal Kajian Keislaman Dan Kemasyarakatan, 3.1 (2018), 100.

xxviii Nur Rois, 'PENANAMAN NILAI NILAI NASIONALISME DALAM PENDIDIKAN PONDOK PESENTREN MIFTAHUL ULUM UNGARAN TIMUR KABUPATEN SEMARANG', SOSIO DIALEKTIKAJurnal Ilmu Sosial-Humaniora, 2.1 (2017), 83-100.

xxix Amiruddin Mustam, 'PESANTREN DALAM DINAMIKA Studi Pada Peranan As'adiyah Dalam Pengembangan Pendidikan', $A L$ ISHLAH, XV.1 (2017), 16.

xxx Ahmad Khori, 'Manajemen Pesantren Sebagai Khazanah Tonggak Keberhasilan Pendidikan Islam', Manageria: Jurnal Manajemen Pendidikan Islam, 2 (2017), 127-53.

xxxi Siti Ma'rifah dan Muhamad Mustaqim, 'PESANTREN SEBAGAI HABITUS PERADABAN ISLAM INDONESIA', Jurnal Penelitian, 9.2 (2015), 347-66.

xxxii Fauzan, 'URGENSI KURIKULUM INTEGRASI DI PONDOK PESANTREN DALAM MEMBENTUK MANUSIA BERKUALITAS', FIKROTUNA: Jurnal Pendidikan Dan Manajemen Islam, 6 (2017), 600-617.

xxxiii Abu Darda, 'Integrasi Ilmu Dan Agama: Perkembangan Konseptual Di
Indonesia', Jurnal At-Ta'dib, 10 (2015), 37.

xxxiv Udi Fakhruddin, Ending Bahruddin, and Endin Mujahidin, 'Konsep Integrasi Dalam Sistem Pembelajaran Mata Pelajaran Umum Di Pesantren', 7.2 (2018), 214-32 $<$ https://doi.org/10.32832/tadibuna. v7i2.1394>.

xxxv Muhammad Fathurrohman, 'PENGEMBANGAN BUDAYA RELIGIUS DALAM MENINGKATKAN MUTU PENDIDIKAN', TA'ALLUM, 4.1 (2016), 19-42.

xxxvi Itah Miftahul Ulum, 'DESAIN PENDIDIKAN AGAMA ISLAM DI PERGURUAN TINGGI UMUM BERBASIS EVOLUSI BUDAYA', Jurnal Pendidikan Agama Islam, Vol. XIII, (2016), 53-64.

xxxvii 'Pengaruh Pendidikan Agama Islam Dan Budaya Religius Sekolah Terhadap Kecerdasan Emosional Dan Spiritual Siswa Oleh: Zakaria Firdausi*', 5.2 (2017), 46-55.

xxxviii Muhammad Husnur Rofiq Muhammad Anas Ma`arif, 'Pola Pengembangan Kurikulum Pendidikan Pesantren Berkarakter: Studi Implementasi Pendidikan Berkarakter Di Pondok Pesantren Nurul Ummah Mojokerto', Tadris, 13 (2018), 1-16.

xxxix John W Creswell, Research Design; Pendekatan Kualitatif, Kualitatif, Dan Mixed (Yogyajarta: Pustaka Pelajar, 2003).

xl Lexy J. Moeloeng, Metode Penelitian Kualitatif Edisi Revisi, (Bandung: Remaja Rosda Karya, 2013).6.

xli P. Joko Subagyo, Metode Penelitian Dalam Teori Dan Praktek (Jakarta: Rineka Cipta).

xlii Umar Sidiq, 'ORGANISASI PEMBELAJARAN PADA PONDOK PESANTREN Di ERA GLOBAL', Cendekia, Vol. 12 (2014), 127.

xliii Akmal Mundiri, 'Transformasi Representasi Identitas Kepemimpinan Kyai Dalam Hubungan Atasan Dan Bawahan', Al-Idarah: Jurnal Kependidikan Islam VIII (II), 2018, 235. 
xliv Hayati.

xlv Muhammad Munif, 'Strategi Internalisasi Nilai-Nilai PAI Dalam Membentuk Karakter Siswa', Edureligia, 1 (2017), 1-12.

xlvii Mustiningsih Ainur Rifqi, Ali Imron, 'MANAJEMEN ALUMNI DI PONDOK PESANTREN MODERN DAN SALAF (STUDI DI PONDOK PESANTREN NURUL JADID DAN PONDOK PESANTREN SIDOGIRI)', 1 (2016), 686-91.

xlviii Hefny Razaq dkk, Profil Singkat \& Riwayat Almarhumin Pondok Pesanntren Nurul Jadid (Probolinggo: Humas Sekretariat Pondok Pesantren Nurul Jadid, 2016).

${ }^{x l i x}$ H. Hasan Baharun, 'DESENTRALISASI DAN IMPLIKASINYA TERHADAP PENGEMBANGAN SISTEM PENDIDIKAN ISLAM', Jurnal iImu Tarbiyah 'At-Tajdid', 1 (2012), 241-54.

${ }^{1}$ M. Mansyur Amin, 'KH. ZAINI MUN'IM (Pengabdian Dan Karya Tulisnya)' (yogyakarta: LKPSM, 1996), p. 125.

${ }^{\text {li }}$ Moh. Rifa'i, 'Kajian Masyarakat Beragama Persepektif Pendekatan Sosiologis', Al-Tanzim, 2 (2018), 18-26.

lii A Rusdiana, 'THE IMPLEMENTATION OF NATIONAL STANDARDBASED CURRICULUM IN PRIVATE ISLAMIC HIGHER EDUCATION: LEADERSHIP IMPACT', Jurnal Pendidikan Islam, 2018, 87-98 $<$ https://doi.org/10.15575/jpi.v4i1.2 $116>$.

liii Abu Bakar, Sinergi Pesantren Dan Perguruan Tinggi,( Studi Pengembangan Kurikulum Ma'had Sunan Ampel Al-Ali Malang (Malang: Humas Sekretariat Pondok Pesantren Nurul Jadid,).

Iv Yeti Nurizzati Moh. Ulinnuha1, Mahdi2, 'INTERNALISASI NILAI-NILAI SOSIAL PADA KALANGAN SANTRI DI PONDOK PESANTREN RAUDLATUT THOLIBIN PADA MASYARAKAT DESA BABAKAN KECAMATAN CIWARINGIN KABUPATEN
CIREBON', Jurnal Edueksos, V (2016), 79-98.

lvi Uci Sanusi, 'PENDIDIKAN KEMANDIRIAN DI PONDOK PESANTREN (StudiMengenai Realitas Kemandirian Santri Di Pondok Pesantren Al-Istiqlal Cianjur Dan Pondok Pesantren Bahrul Ulum Tasikmalaya)', Jurnal Pendidikan Agama Islam -Ta'lim, 10.2 (2012), 12339.

lvii Ismail Suardi Wekke; Siddin; Ibrahim Kasop, 'PESANTREN, MADRASAH, SEKOLAH, DAN PANTI ASUHAN: POTRET LEMBAGA PENDIDIKAN ISLAM MINORITAS MUSLIM', At - Tajdid: Ju R Nal Ilmu Tar Biyah, 6 (2017), 132.

lviii 3 Hendri a, 1, Cecep Darmawan b, 2, Muhammad Halimi c, 'Penanaman Nilai-Nilai Pancasila Pada Kehidupan Santri Di Pondok Pesantren', Jurnal Civics: Media Kajian Kewarganegaraan, 15.2 (2018), 103 - 110.

Samsudin Salim \& Toha Makhshun, 'MANAJEMEN PESANTREN MAHASISWA', AL-Fikril Jurnal Studi Dan Penelitian Pendidikan Islam, 1 (2018), 61.

${ }^{1 x}$ M Yusuf, 'Dinamika Integrasi Pesantren Dan Sekolah Dalam Pendidikan Kontemporer Di Indonesia', $A L$ MURABBI, 3 (2017), 178-91. 